\title{
Electrospray Mass Spectrometry of Methanol and Water Solutions Suppression of Electric Discharge with $\mathrm{SF}_{6}$ Gas
}

\author{
Michael G. Ikonomou, Arthur T. Blades, and Paul Kebarle \\ Chemistry Department, University of Alberta, Edmonton, Alberta, Canada
}

An equation by D. P. H. Smith predicts the capillary voltage required for the onset of electrospray (ES). For different solvents the voltage increases with the square root of the surface tension. Water requires a potential that is 1.8 times higher than that for methanol. This is verified experimentally. The higher potential required for water leads to ES in the presence of corona electric discharge. For low total ES plus corona currents, the electrosprayed analyte ion intensity is not adversely affected by the presence of discharge. At high total currents, there is a large decrease of analyte sensitivity. The sensitivity decrease is probably due to adverse space charge effect at high currents. The discharge can be suppressed by adding sulfur hexafluoride to the ambient gas. Both sensitivity and signal stability are improved. However, the sensitivity still remains lower by a factor of $\sim 4$ relative to that observed with methanol. This is attributed to lower efficiency of gas-phase ion formation from charged water, relative to methanol, droplets. (J Am Soc Mass Spectrom $1991,2,497-505)$

$\mathrm{E}$ lectrospray (ES) ionization for the purpose of mass spectrometric analysis is most easily executed with methanol as a solvent [1-5]. Acetonitrile is also a solvent with which both good sensitivity and signal stability are easily obtained. Neat water is very desirable from an analytical standpoint, because it is the ideal solvent for ionic (electrolyte) analytes and particularly for multiply charged ions. On the other hand, the ES of neat water solutions leads to low sensitivity and poor signal stability and therefore one generally restricts oneself to watermethanol mixtures [1-5].

The formation of the charged droplets at the capillary tip and the formation of gaseous ions from the charged droplets are the two key processes in ES. The problems encountered with water as compared to methanol and acetonitrile may be associated with either one or both of the above stages. The major purpose of the present work is to explore which stage is responsible and for what reason. Once these factors are elucidated one might then also be able to select possible remedies on a rational basis.

Smith [6], in a theoretical and experimental study of ES, has derived an equation that predicts the electric field $E_{o n}$ at the capillary tip for the onset of ES; see eq 1 , where $\gamma$ is the surface tension of the solvent,

Address reprint requests to Paul Kebarle, Chemistry Department, University of Alberta, Edmonton, Alberta, Canada T6G 2 G2.

$$
E_{\mathrm{on}}=\left(\frac{2 \gamma \cos \theta}{\epsilon_{0} r_{c}}\right)^{1 / 2}
$$

$\theta$ is the half angle of the liquid cone at the tip of the capillary $\left(\theta=49.3^{\circ}\right.$, see Taylor [7] and Smith [6]), $\epsilon_{0}=8.8 \times 10^{-12} \mathrm{~J}^{-1} \mathrm{C}^{2} \mathrm{~m}^{-1}$ is the permittivity of vacuum, and $r_{c}$ is the outer radius of the capillary.

The surface tension $\gamma$ values are given below.

$\begin{array}{lccc}\text { Solvent } & \mathrm{CH}_{3} \mathrm{OH} & \mathrm{CH}_{3} \mathrm{CN} & \mathrm{H}_{2} \mathrm{O} \\ \text { Surface tension } \gamma,\left(\mathrm{N} \mathrm{m}^{-1}\right) \times 10^{3} & 22 & 30 & 72\end{array}$

Taking the square root of the surface tension ratio, one finds that the onset field and thus also onset voltage for water is 1.8 times higher than that for methanol.

The operating ES capillary voltages need to be some 100-500 V higher than the ES onset voltages [5], so one might suspect that the high voltage required for charged water droplet formation is the cause for the poorer performance of ES with water as solvent. Thus, practitioners of ES know that even for methanol as solvent, the operational ES voltage is quite close to corona discharge conditions [1-5]. Therefore, a corona discharge may be occurring simultaneously with ES with water as solvent because of the higher capillary voltage required, and the discharge may be responsible for the low sensitivity and stability encountered with that solvent. 
Electrical discharges can be suppressed by suitable choice of ambient gas and it was this idea that provided the additional impetus for the present experimental work. We chose to suppress the discharge by the addition of sulfur hexafluoride $\left(\mathrm{SF}_{6}\right)$ gas to the ambient air. $\mathrm{SF}_{6}$ is both relatively nontoxic and odorless and has found widespread use for the suppression of electrical discharges $[8,9]$.

The arrangements used to provide a suitable $\mathrm{SF}_{6}$ concentration for the suppression of the discharge are described in the Experimental section. As will be seen in the Results and Discussion section, the suppression of electric discharge was successful and higher signal stability and sensitivity was achieved by this means.

An answer to the question whether the problem when water is used is due to the charged droplet formation stage or the gas-phase ion formation stage or both is also provided in the Discussion.

\section{Experimental}

The instrument used in this study was a triple quadrupole mass spectrometer (TAGA model 6000E, SCIEX, Thornhill, ON) equipped with an atmospheric pressure ionization (API) source. Detailed schematic diagrams of this apparatus were given in our earlier ES work $[5,10]$. The instrument was operated in the positive ion mode, and ES was used as the ionization source.

The ES assembly used in the present work is shown in Figure 1. The inner, stainless steel capillary carries the solution. The annular space between the inner capillary and the outer tube is for the $\mathrm{SF}_{6}$ gas. Analyte solution was supplied to the tip of the assembly by 0.003 -in. i.d. and 0.011-in. o.d. silica tubing, which was joined to the stainless steel capillary of the spray by means of the zero dead volume union, as shown in Figure 1. The solutions were supplied to the assembly by a motor-driven syringe (model 341A, SAGE Instruments, Cambridge, MA). The flow rate generally was $20 \mu \mathrm{L} / \mathrm{min}$ and the solvents used were either $100 \%$ methanol or $99 \%$ water $1 \%$ methanol.

The outer, much wider concentric tube 0.048-in. i.d., 0.U65-in, o.d. was kept back from the tip of the inner capillary (see Figure 1). This geometry leads to a minimal effect of the electric field at the inner capillary tip. For evaluation of the electric field, see eq 2 in the Appendix. The $\mathrm{SF}_{6}$ flow rate was up to $400 \mathrm{~mL} / \mathrm{min}$. The wide diameter and low flow rate may be expected to lead to a low gas flow velocity near the inner capillary tip and to a minimal disturbance of the conventional ES conditions apart from the suppression of the corona discharge by the $\mathrm{SF}_{6}$ gas.

Introducing the $\mathrm{SF}_{6}$ concentrically proved to be the most effective way of suppressing corona discharge(s) and minimizing the amount of $\mathrm{SF}_{6}$ used. Introducing $\mathrm{SF}_{6}$ via a hole on the lid of the API source plenum chamber proved to be much less effective in suppressing corona. The required amount was much higher because the entire chamber needed to be supplied with $\mathrm{SF}_{6}$. The $\mathrm{SF}_{6}$ flow rate was measured with a specially calibrated flow meter.

The capillary assembly (Figure 1) was mounted inside the API plenum chamber, such that the capillary tip was $4 \mathrm{~cm}$ away from the wall of the interface chamber $[5,10]$. This wall, which is at $650 \mathrm{~V}$ potential, is the counterelectrode. The total current (TC) arriving at this electrode was measured with a current meter. This is the current given in part a of Figures 2, 3, 5-7.

The wall of the interface chamber has a central,

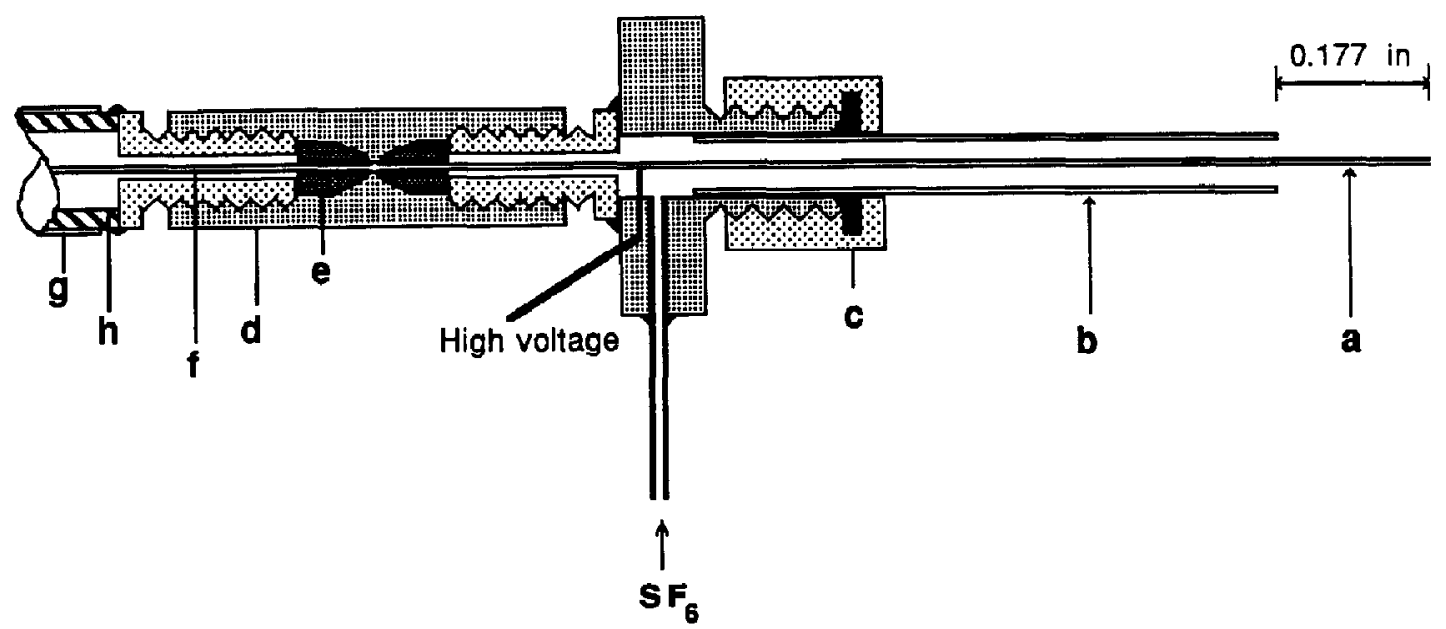

Figure 1. ES device used allowing $\mathrm{SF}_{6}$ gas flow around capillary tip. (a) Inner stainless steel (ss) capillary through which solution flows, 0.004 in, i.d., 0.009 in. $0 . d$. (b) Outside ss tube for $\mathrm{SF}_{6}$ gas flow, 0.048 in. i.d., 0.065 in. o.d. (c) $1 / 16$ in. ss swagelock union (d) $1 / 16$ in. ss zero deal volume union. (e) Vespel ferrule. (f) Silica tubing 0.003 in. i.d., 0.011 in. o.d. (g) Shrinkable teflon. (h) $3 / 16$-in, ss tubing, 8 in, long, welded onto union nut. 
4-mm diameter orifice that allows some of the ions to enter the $\mathrm{N}_{2}$ interface gas chamber. The ES capillary tip was mounted $\sim 1.5 \mathrm{~cm}$ off axis from the central orifice, as was the case in previous studies $[5,10]$. The interface chamber contains ultrapure $\mathrm{N}_{2}$ gas supplied at a $0.5-\mathrm{L} / \mathrm{min}$ flow rate. The ions drift through the chamber to the wall of the vacuum chamber. They enter the vacuum region through a $100-\mu \mathrm{m}$ diameter orifice, which is at $60-\mathrm{V}$ potential. The potentials of the first two electrodes in the vacuum region where the gas is still expanding are 33 and $30 \mathrm{~V}$. The accelerated ions in this region experience collisional activation, which leads to loss of clustered solvent molecules. The ions reaching the mass analysis region had only one or no solvent molecules attached to them [10].

Mass analysis was obtained with the third quadruple $Q_{3}$ (300 resolution) and $Q_{1}, Q_{2}$ in the radiofrequency only mode. lon counting was used for determination of the intensities of the mass analyzed ions. The counter becomes nonlinear above $\approx 7 \times 10^{5}$ counts/s. Therefore, for the quantitative measurements, when the signal obtained with $Q_{3}$ exceeded $7 \times 10^{5}$ counts/s, both quadrupoles $Q_{1}$ and $Q_{3}$ were used in the resolving mode, reducing in this manner the ion signal. The intensities obtained were then adjusted to the intensity that would have been observed with only $\mathrm{Q}_{3}$ in the resolving mode.

The $\mathrm{SF}_{6}$ used was of chemically pure grade and was purchased from LINDE. The water solvent was doubly distilled and the methanol was of high performance liquid chromatography grade. The potential to the capillary was provided from a regulated constant voltage supply.

Whereas the capillary potentials for onset of ES were well reproducible, the potentials for onset of the electric discharges were not. In some experiments discharge onsets occurred at higher potentials. Thus, discharge onset in pure methanol in the absence of $\mathrm{SF}_{6}$ could occur at voltages higher by as much as $1 \mathrm{kV}$ than the $6 \mathrm{kV}$ onset observed in Figure 5 .

\section{Results and Discussion}

The effectiveness of the $\mathrm{SF}_{6}$ gas to suppress an electric discharge is illustrated in Figure 2. Methanol solvent containing $10^{-5} \mathrm{~mol} / \mathrm{L}(\mathrm{M})$ of analyte, $\mathrm{BHCl}$, where $B=$ cocaine, was electrosprayed. In one set of experiments the capillary potential was $6 \mathrm{kV}$, which is -1 $\mathrm{kV}$ higher than the potential $(5-5.3 \mathrm{kV})$ normally used $[5,10]$. Figure 2a shows the drop of TC (see Experimental) as the $\mathrm{SF}_{6}$ flow is increased. The two major ions, which represent close to $90 \%$ of the total ion intensity observed with the mass spectrometer, are shown in Figure $2 \mathrm{~b}$. At zero and low $\mathrm{SF}_{6}$ flow rates $\mathrm{CH}_{3} \mathrm{OH}_{2}^{+}$is by far dominant. It can be predicted on the basis of previous work $[5,10,11]$ that a corona discharge in atmospheric air containing some methanol vapor will lead to $\mathrm{CH}_{3} \mathrm{OH}_{2}^{+}$ions. In the absence
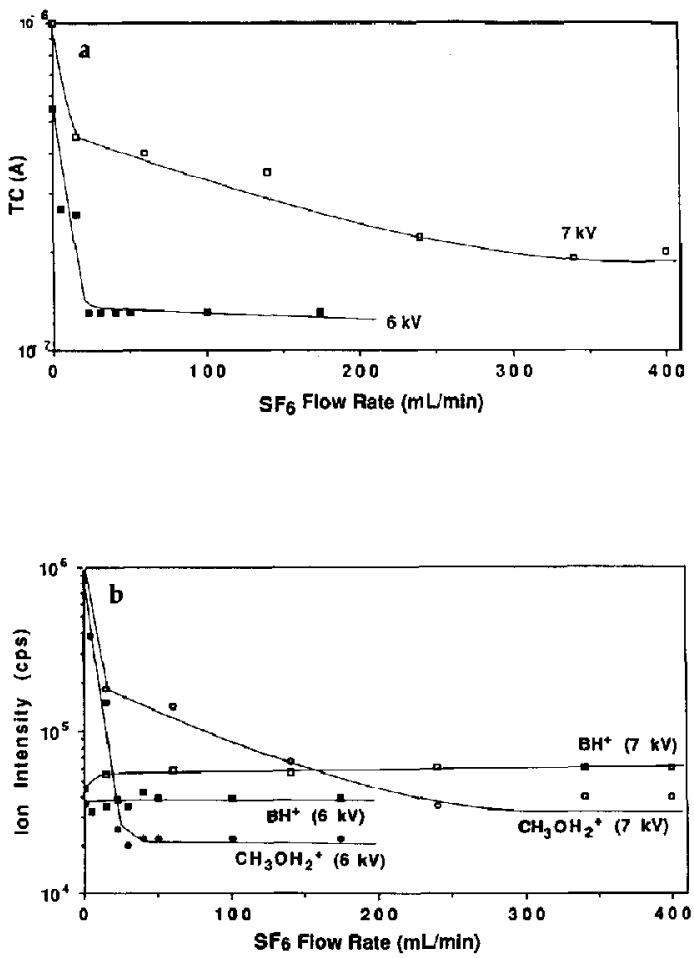

Figure 2. Effect of $\mathrm{SF}_{6}$ gas flow rate on ES TC and major mass analyzed ions. $\mathrm{TC}$ and $\mathrm{CH}_{3} \mathrm{OH}_{2}^{+}$ions at low $\mathrm{SF}_{6}$ flow rates are due to electric discharge. Conditions: 6 and $7 \mathrm{kV}$ capillary potential. Distance to electrode: $4 \mathrm{~cm}$. Methanol solvent with $10^{-5} \mathrm{M} \mathrm{BIICl}$ where $\mathrm{B}=$ cocaine. Flow rate: $20 \mu \mathrm{L} / \mathrm{min}$.

of methanol, $\mathrm{H}_{3} \mathrm{O}^{+}$ions arc the dominant products of electric discharge in atmospheric air [11]. These will engage in proton transfer to methanol when methanol is present because of the higher proton affinity of methanol [11]. Previous ES work with methanol as solvent $[5,10]$ showed that the intensity of $\mathrm{CH}_{3} \mathrm{OH}_{2}^{+}$ ions always increases in the presence of corona discharge.

Beyond $40 \mathrm{~mL} / \mathrm{min} \mathrm{SF}_{6}$ flow, $\mathrm{CH}_{3} \mathrm{OH}_{2}^{+}$becomes a minor ion and remains constant. The shape of the TC and $\mathrm{CH}_{3} \mathrm{OH}_{2}^{+}$intensity curves, with increasing $\mathrm{SF}_{6}$, flow is very similar and this demonstrates that the two are closely related and that both reflect the suppression of the corona discharge at high $\mathrm{SF}_{6}$ concentrations.

Also shown in Figure 2 are the results observed when the capillary potential was set at $7 \mathrm{kV}$. On the whole, the intensity changes are similar. However, the suppression of the discharge requires higher $\mathrm{SF}_{6}$ flows and seems to occur in two stages, rapid partial suppression at $40 \mathrm{~mL} / \mathrm{min}$, and then slow changes with essentially complete suppression at $300 \mathrm{~mL} / \mathrm{min}$.

Results from an analogous set of experiments but with water as solvent are shown in Figure 3. The high $\mathrm{TC}$ at low $\mathrm{SF}_{6}$ flow rates are due to corona discharge. 

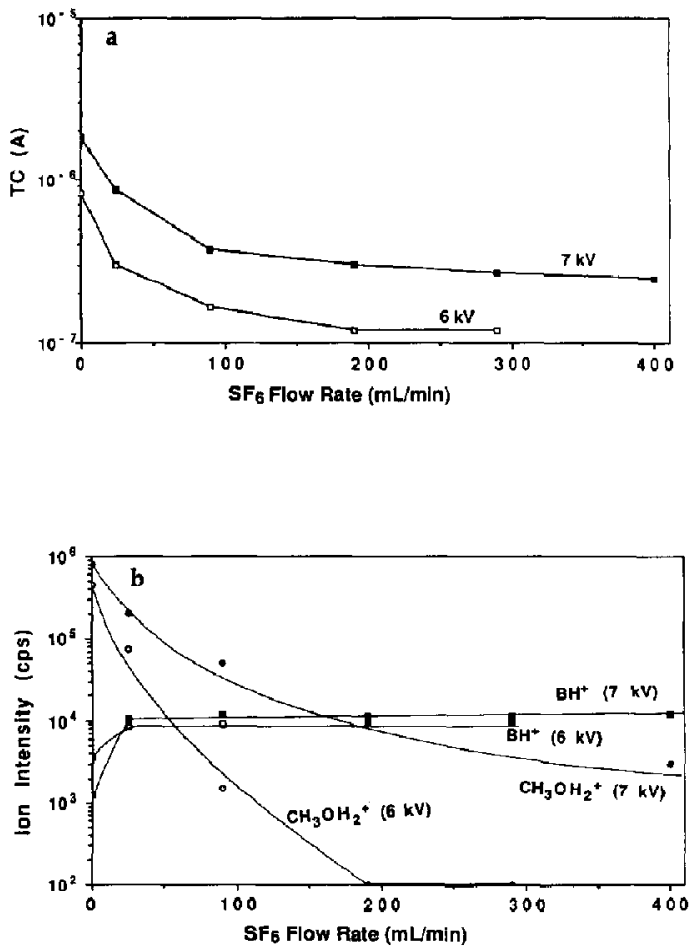

Figure 3. Effect of $\mathrm{SF}_{6}$ flow rate on $\mathrm{TC}$ and selected mass analyzed ions, Capillary potential 6 and $7 \mathrm{kV}$. Solution: $10^{-5} \mathrm{M}$ $\mathrm{BHCl}$ where $\mathrm{B}=$ cocaine in water containing $1 \%$ methanol. TC and $\mathrm{CH}_{3} \mathrm{OH}_{2}^{+}$at low $\mathrm{SF}_{6}$ flow rates due to electric discharge.

Before discussing the data in Figure 3 in more detail, we take a look at the mass spectra observed at $7 \mathrm{kV}$ without and with $\mathrm{SF}_{6}$. These are shown in Figure $4 \mathrm{a}$ and $b$. The $\mathrm{H}_{3} \mathrm{O}^{+}\left(\mathrm{H}_{2} \mathrm{O}\right)_{n}$ ions observed in absence of $\mathrm{SF}_{6}$ are almost entirely due to electric discharge [11]. The $\mathrm{NH}_{4}^{+}$ion is formed by proton transfer from the hydronium ions to traces of $\mathrm{NH}_{3}$ gas present in atmospheric air. This is a very efficient reaction due to the high proton affinity of ammonia [11]. The aqueous solution used for the experiments, on which Figures 3 and 4 are based, contained $1 \%$ methanol. In the presence of methanol some proton transfer from the hydronium ions to methanol molecules occurs in the gas phase. The $\mathrm{CH}_{3} \mathrm{OH}_{2}^{+}$observed were used as "discharge indicators" for the aqueous solutions, see Figures 3 and 5-7. The analyte ion $\mathrm{BH}^{+}, m / z 304$, is barely visible in Figure $4 a$.

In the presence of $\mathrm{SF}_{6}$ (Figure $4 \mathrm{~b}$ ) the ES-produced ions $\mathrm{Na}^{+}\left(\mathrm{H}_{2} \mathrm{O}\right)_{n}$ and $\mathrm{BH}^{+}$are dominant. The $\mathrm{Na}^{+}$ ions are due to sodium salt impurities at the $0.5 \times 10^{-5}$ $M$ levels in the solution $[5,10]$. The $\mathrm{BH}^{+}$peak is relatively much smaller than the sum of the $\mathrm{Na}^{+}$core ion peaks, even though the $\mathrm{BH}^{+}$concentration in the solution is probably twice as large. The transmission of the quadrupole decreases with mass [11] and this effect should be responsible for most if not all of the observed intensity loss for the $\mathrm{BH}^{+}$ion.
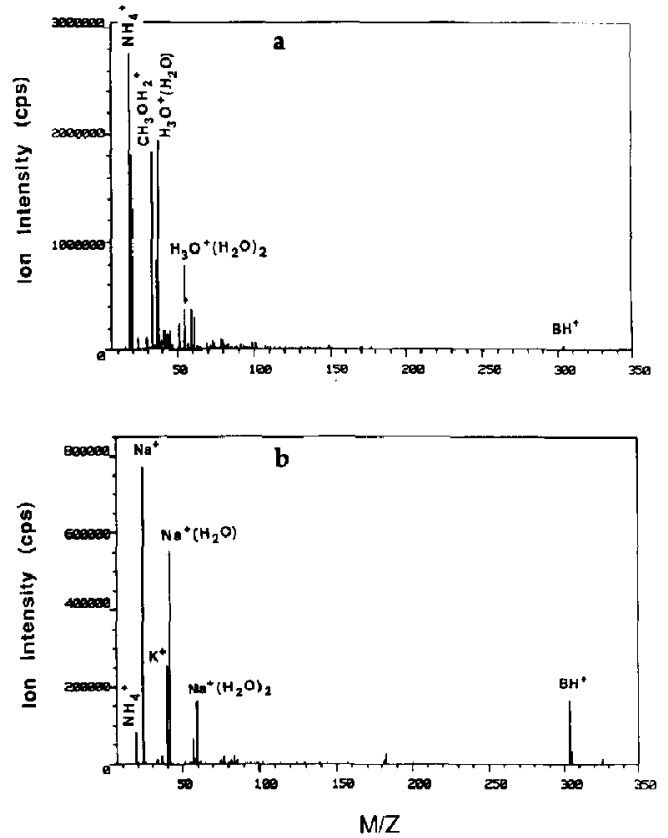

Figure 4. (a) Observed mass spectrum on ES of a solution in water under conditions where an electric discharge dominates ion production. Major discharge-produced ions and mass-tocharge ratio in parens: $\mathrm{NH}_{4}^{+}$(18), $\mathrm{H}_{3} \mathrm{O}^{+}(19), \mathrm{CH}_{3} \mathrm{OH}_{2}^{+}$(33), $\mathrm{NH}_{4}^{+}\left(\mathrm{H}_{2} \mathrm{O}\right)(36), \mathrm{H}_{3} \mathrm{O}^{+}\left(\mathrm{H}_{3} \mathrm{O}\right)(37)$. Analyte ion due to ES BH ${ }^{+}$ (304). Conditions: capillary voltage $7 \mathrm{kV}, \mathrm{BHCl} 10^{-5} \mathrm{M}$. (b) Observed mass spectrum on ES of same solution under same conditions as for data in a, but with discharge suppression by a flow of $\mathrm{SF}_{6}$ at $500 \mathrm{~mL} / \mathrm{min}$. ES-produced ions: $\mathrm{Na}^{+}$(23), $\mathrm{Na}^{+}\left(\mathrm{H}_{2} \mathrm{O}\right)(41), \mathrm{Na}^{+}\left(\mathrm{H}_{2} \mathrm{O}\right)_{2}(59)$ due to $\mathrm{Na}$ impurity salts, $\mathrm{BH}^{+}$ (304) due to analyte. Ion intensities not corrected for mass-dependent transmission, which decreases with mass.

The total current and ion intensities changes with $\mathrm{SF}_{6}$ shown in Figure 3 indicate almost complete suppression of the discharge at $6 \mathrm{kV}$. At $7 \mathrm{kV}$ the TC is found to be about two times higher relative to that at $6 \mathrm{kV}$, and the discharge indicating ion $\mathrm{CH}_{3} \mathrm{OH}_{2}^{+}$is also of relatively high intensity even at the largest $\mathrm{SF}_{6}$ flows used. An increase of ES-produced TC can be expected when the capillary potential is increased from 6 to $7 \mathrm{kV}$, however; this increase is expected [5] to be much smaller than the factor of two observed in Figure 3. It appears therefore that the electric discharge is not completely suppressed at $7 \mathrm{kV}$ even for the highest $\mathrm{SF}_{6}$ flows used.

The observed $\mathrm{BH}^{+}$intensities in Figure 3 show an increase with $\mathrm{SF}_{6}$ flow. The increase is by a factor of -3 at $6 \mathrm{kV}$ and -10 at $7 \mathrm{kV}$. Additional evidence for such sensitivity changes involving ES-produced ions is provided by the experiments at variable capillary potentials described below.

Total currents and mass analyzed intensities as functions of the applied capillary voltage for solutions of $\mathrm{BHCl}$, in methanol and in water, in the presence and absence of $\mathrm{SF}_{6}$ are shown in Figures 5 and 6 . The onset voltages, $V_{o n}$, for ES with methanol or water as 

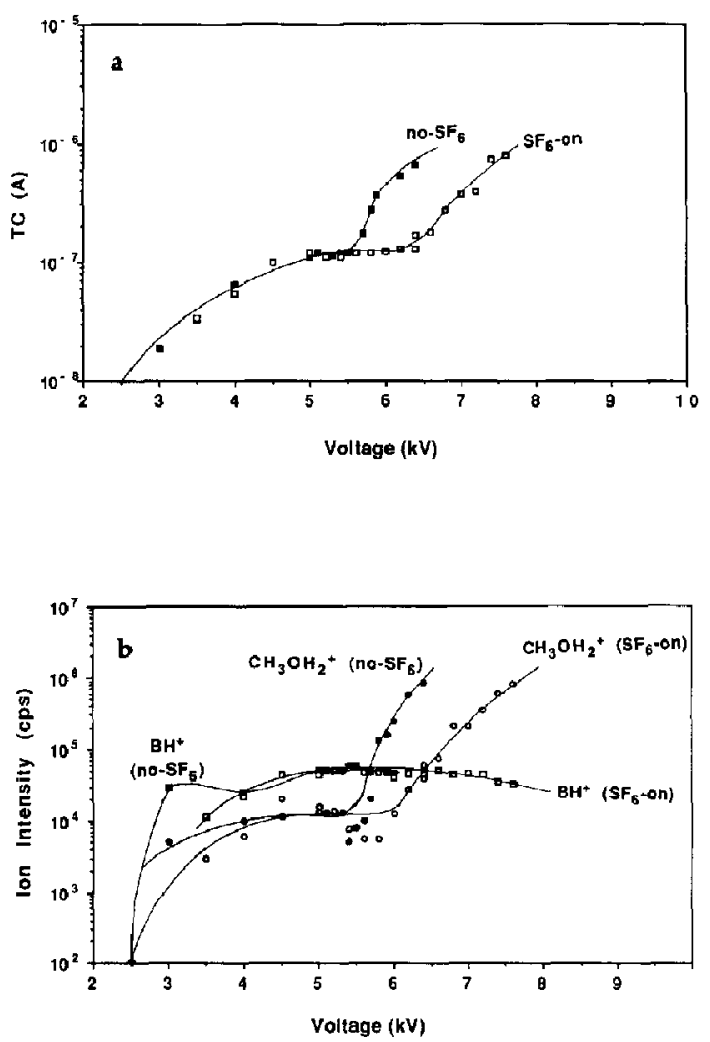

Figure 5. ES TC and major mass analyzed ions $\mathrm{BH}^{+}$and $\mathrm{CH}_{3} \mathrm{OH}_{2}^{+}$as a function of capillary potential, without $\mathrm{SF}_{6}$ and with $\mathrm{SF}_{6}$. Methanol solvent with $10^{-5} \mathrm{M}$ BHCl, where $\mathrm{B}=$ cocaine. Onset of electric discharge indicated by sharp rise of TC and $\mathrm{CH}_{3} \mathrm{OH}_{2}^{+}$currents. $\mathrm{SF}_{6}$ flow rate: $40 \mathrm{~mL} / \mathrm{min}$. Solution flow rate $20 \mu \mathrm{L} / \mathrm{min}$.

solvent can be obtained from the voltage at the current onset. These are $-2.6 \mathrm{kV}$ for methanol and $\sim 4.4 \mathrm{kV}$ for water. However, these values must be reduced to $2.0 \mathrm{kV}(\mathrm{MeOH})$ and $3.8 \mathrm{kV}\left(\mathrm{H}_{2} \mathrm{O}\right)$ because the counter electrode (see Experimental) is at $0.6 \mathrm{kV}$.

The voltage ratio obtained:

$$
V_{\text {on }}\left(\mathrm{H}_{2} \mathrm{O}\right) / V_{\text {on }}\left(\mathrm{CH}_{3} \mathrm{OH}\right)=1.9
$$

is close to the ratio of 1.8 predicted by the square root of the surface tension ratio (see eq 1). As shown in the Appendix, eq 1 from Smith [6] predicts quite closely not only the ratio but also the actual values of $V_{o n}$ for methanol and water.

The TC with methanol (see Figure 5a) remains independent of the presence or absence of $\mathrm{SF}_{6} \mathrm{up}$ to $-5.5 \mathrm{kV}$. Above that potential a corona discharge sets in in the absence of $\mathrm{SF}_{6}$. The discharge is indicated not only by a sudden increase of TC but also by a sudden increase of the $\mathrm{CH}_{3} \mathrm{OH}_{2}^{+}$ion intensity, which is due to the corona discharge. In the presence of $\mathrm{SF}_{6}$, provided at a modest flow rate of $40 \mathrm{~mL} / \mathrm{min}$
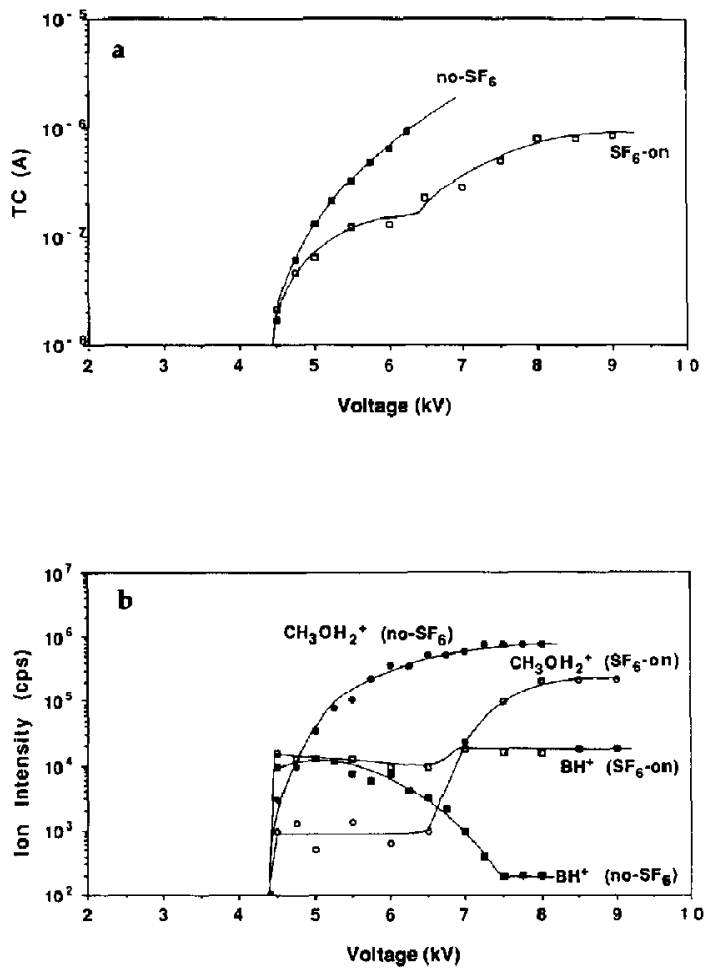

Figure 6. Same conditions as in Figure 5 but with water containing $1 \%$ of methanol as solvent. Onset of ES occurs at higher potential, $-4.4 \mathrm{kV}$, than that required for methanol, $-2.6 \mathrm{kV}$; see Figure 5. Decrease of $\mathrm{BH}^{+}$signal at high electric discharge current in absence of $\mathrm{SF}_{6}$, believed to be due to adverse space charge effect.

(see Figure 2 for comparison), the onset of corona discharge is delayed from 5.5 to $6 \mathrm{kV}$. Furthermore, the onset of discharge in this case is more gradual. The analyte ion, $\mathrm{BH}^{+}$intensity, which is produced by $\mathrm{ES}$, decreases only slightly as the discharge increases the TC to $10^{-6} \mathrm{~A}$. However, a small increase of $\mathrm{BH}^{+}$ intensity is expected with increase with capillary voltage in the absence of electric discharge [5]. Therefore, the intensity changes in Figure 5 are consistent with a moderate decrease of $\mathrm{BH}^{+}$signal with increases of TC due to corona discharge when the TC begins to approach $10^{-6} \mathrm{~A}$.

A large scatter of the $\mathrm{CH}_{3} \mathrm{OH}_{2}^{+}$ion intensity is noticeable in Figure $5 \mathrm{~b}$ in the $5-6-\mathrm{kV}$ region. In this region the onset of the discharge was intermittent. Simultaneous changes of the type of spray at the capillary tip were also observed. Thus the angle of the spreading mist of droplets increased and decreased intermittently, the spray settling into a wider angle at higher voltages. The capillary tip is "off center" from the sampling hole (see Experimental), so these fluctuations in spray angle probably lead to the observed fluctuations of ion intensity.

The TC and the mass analyzed ion intensity plots for water as solvent (Figure 6) are quite different from 
those for methanol. Not only is the ES onset for water higher, but the shape of the TC curve in the absence of $\mathrm{SF}_{6}$ shows no break. The same is true for the intensity of the discharge indicator ion $\mathrm{CH}_{3} \mathrm{OH}_{2}^{+}$. This must mean that, in the absence of $\mathrm{SF}_{6}$, there is an electric discharge component to the TC already at the onset of ES.

In the presence of a moderate flow of $\mathrm{SF}_{6}$, both the $\mathrm{TC}$ and the $\mathrm{CH}_{3} \mathrm{OH}_{2}^{+}$current have breaks that clearly indicate the onset of corona discharge at $-6.5 \mathrm{kV}$. Thus, for water in the absence of $\mathrm{SF}_{6}$ the onset of discharge $(\sim 4.5 \mathrm{kV})$ occurs earlier than is the case for methanol $(\sim 5.5 \mathrm{kV})$. However, the same flow of $\mathrm{SF}_{6}$ delays the discharge onset to about the same voltage (6-6.5 kV) for both solvents. The reasons for the earlier corona onset for water in the absence of $\mathrm{SF}_{6}$ are not clear. Possibly, corona discharge occurs earlier for air containing water rather than methanol vapor.

The $\mathrm{BH}^{+}$intensity (Figure 6 ) decreases by a factor of -100 as the discharge TC increases in the absence of $\mathrm{SF}_{6}$. It should be noted that the $\mathrm{BH}^{+}$intensity decrease becomes very noticeable at the point where the TC approaches and goes above $\sim 10^{-6} \mathrm{~A}$. But, in the presence of $\mathrm{SF}_{6}$, which maintains the TC below $10^{-6} \mathrm{~A}$, the $\mathrm{BH}^{+}$intensity is not strongly affected by the presence of some electric discharge. Analogous decreases of $\mathrm{BH}^{+}$intensity with increasing discharge current were observed in Figure 3.

The decrease of $\mathrm{BH}^{+}$intensity at high $\mathrm{TC}_{\text {, }}$ produced by the electric discharge, is probably due to the adverse effect of space charge. For both ES and corona discharge, most of the space between the capillary and the counterelectrode contains unipolar, positive charges. An increase of current due to discharge is expected to decrease the fraction of ions that cross from atmospheric pressure through the sampling orifice leading to the vacuum of the mass analysis region [12]. Therefore, one expects a decrease of mass analyzed ES ions, e.g., $\mathrm{BH}^{+}$intensities, even if the rate of production of ES ions by the ES device is unaffected by the discharge. From the results in Figures 2, 3,5 , and 6 it appears that the space charge effect becomes significant for a TC above $10^{-6} \mathrm{~A}$.

The results shown in Figures 7 and 8 illustrate the observed total ion current and mass analyzed $\mathrm{BH}^{+}$ intensity changes with capillary voltage for water as solvent, when nol only $\mathrm{BHCl}$ but also a second electrolyte at relatively much higher concentration is present in the solution. Results obtained in the presence of $5 \times 10^{-3} \mathrm{M} \mathrm{NaCl}$ are given in Figure 7 . The decrease of $\mathrm{BH}^{+}$, observed in the absence of $\mathrm{SF}_{6}$, with increase of capillary voltage is considerably faster when compared to that observed in the absence of excess electrolyte (see Figure 6). This is attributed to a stronger adverse space charge effect because in the presence of electrolyte the TC is larger, owing to the presence of discharge and to an increased ES current caused by the presence of the $\mathrm{NaCl}$ electrolyte $[5,10]$. Both the $\mathrm{BH}^{+}$and the $\mathrm{Na}^{+}\left(\mathrm{H}_{2} \mathrm{O}\right)$ ion intensity de-
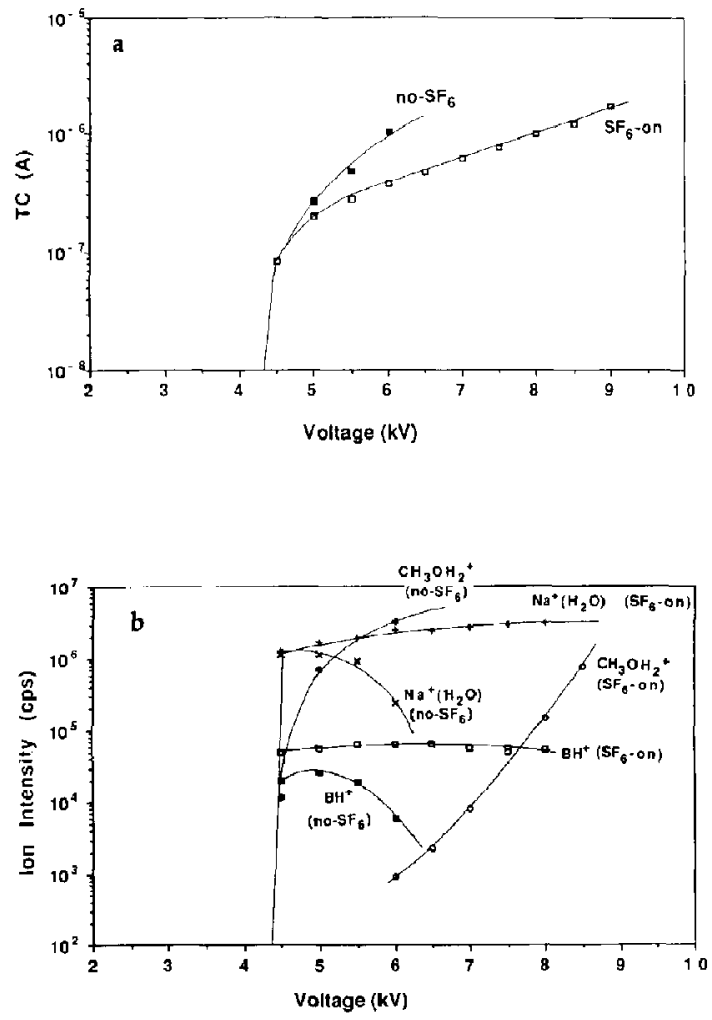

Figure 7. Effect of addition of a second electrolyte $\mathrm{NaCl}$ at $5 \times 10^{-3} \mathrm{M} \mathrm{NaCl}$ to $10^{-5} \mathrm{M}$ aqueous solution of $\mathrm{BHCl}$ with $1 \%$ methanol. Other conditions same as for Figure 6. Suppression of $\mathrm{BH}^{+}$signal in absence of $\mathrm{SF}_{6}$ more severe than in Figure 6 because TCs higher in present case. The TC are due to electric discharge $\left(\mathrm{CH}_{3} \mathrm{OH}_{2}^{+}\right)$and increased ES current due to high $\mathrm{NaCl}$ concentration. $\mathrm{SF}_{6}$ flow: $290 \mathrm{~mL} / \mathrm{min}$.

crease in the absence of $\mathrm{SF}_{6}$ while the intensities for these ions remain approximately constant when the discharge is suppressed with $\mathrm{SF}_{6}$.

The effect observed when the added electrolyte is $5 \times 10^{-3} \mathrm{M}$ ammonium acetate is shown in Figure 8 . As expected, a high $\mathrm{NH}_{4}^{+}$ion intensity is observed. However, the "discharge indicator ion" $\mathrm{CH}_{3} \mathrm{OH}_{2}^{+}$ has disappeared even though discharge is still indicated by the $\mathrm{TC}$ curves, without and with $\mathrm{SF}_{6}$. The absence of $\mathrm{CH}_{3} \mathrm{OH}_{2}^{+}$is easily explained. Previous work [10] has shown that when ammonium salts like ammonium acetate are added as electrolyte at "high," i.e., $>10^{-4} \mathrm{M}$ concentrations, gaseous $\mathrm{NH}_{3}$ is produced, presumably by escape of ammonia from the droplets. The gaseous $\mathrm{NH}_{3}$, which has a higher proton affinity than $\mathrm{H}_{2} \mathrm{O}$ and $\mathrm{CH}_{3} \mathrm{OH}$, abstracts protons from the $\mathrm{H}_{3} \mathrm{O}^{+}$and $\mathrm{CH}_{3} \mathrm{OH}_{2}^{+}$ions in the gas phase. Therefore, the discharge-produced ions $\mathrm{CH}_{3} \mathrm{OH}_{2}^{+}$and $\mathrm{H}_{3} \mathrm{O}^{+}$are converted into $\mathrm{NH}_{4}^{+}$in the presence of ammonium acetate. For this reason no $\mathrm{CH}_{3} \mathrm{OH}_{2}^{+}$, $\mathrm{H}_{3} \mathrm{O}^{+}$ions were detected. The $\mathrm{NH}_{4}^{+}\left(\mathrm{H}_{2} \mathrm{O}\right)$ ion is now the dominant discharge product, so its intensity does 

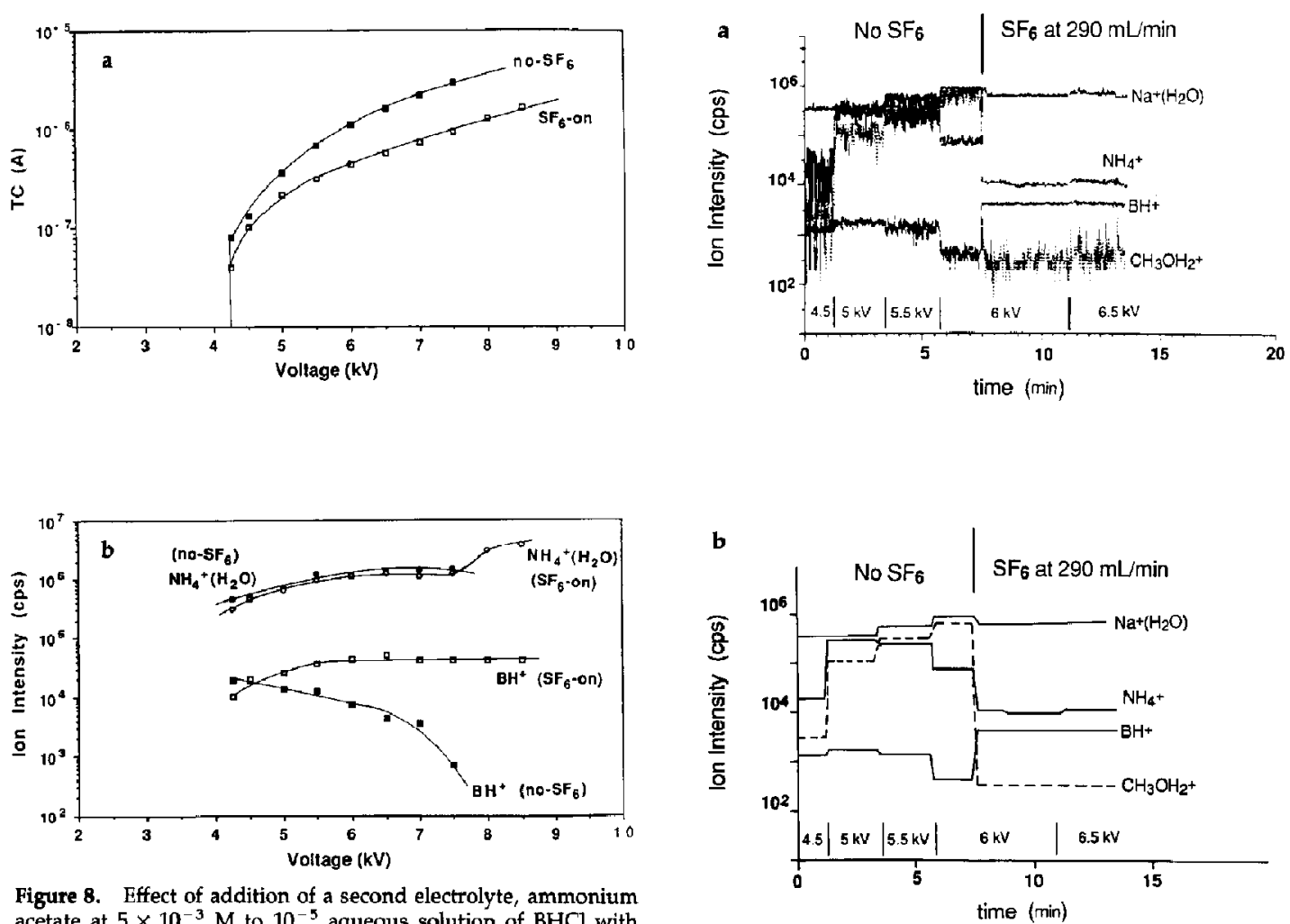

Figure 8. Effect of addition of a second electrolyte, ammonium
acetate at $5 \times 10^{-3} \mathrm{M}$ to $10^{-5}$ aqueous solution of $\mathrm{BHCl}$ with $1 \%$ methanol. Other conditions as for Figure 7. Presence of electric discharge is more difficult to recognize because discharge ions $\mathrm{H}_{3} \mathrm{O}^{+}$and $\mathrm{CH}_{3} \mathrm{OH}_{2}^{+}$react with gaseous $\mathrm{NH}_{3}$, produced from the ammonium acetate, to yield $\mathrm{NH}_{4}^{+}\left(\mathrm{H}_{2} \mathrm{O}\right.$ ) ions.

not decrease with increase of discharge current in the absence of $\mathrm{SF}_{6}$ as was the case for $\mathrm{Na}^{+}\left(\mathrm{H}_{2} \mathrm{O}\right.$ ) (see Figure 7). The adverse effect of space charge in the absence of $\mathrm{SF}_{6}$ is therefore observed only for the $\mathrm{BH}^{+}$ ion.

The observed $\mathrm{BH}^{+}$intensity of ES of the solutions in water (see Figures 6-8) at a lower capillary voltage of $5 \mathrm{kV}$, without $\mathrm{SI}_{6}$ where the electric discharge current is moderate, is not very much lower than that observed at a higher voltage of $6 \mathrm{kV}$, with $\mathrm{SF}_{6}$. Therefore, it can be asked: Is it worthwhile to use $\mathrm{SF}_{6}$ so as to be able to work at higher potentials? An answer is provided by the $\mathrm{BH}^{+}$intensity traces shown in Figure 9. The $\mathrm{BH}^{+}$intensity at $5 \mathrm{kV}$ (no $\mathrm{SF}_{6}$ ) is only 2.3 times lower than that at $6-6.5 \mathrm{kV}$ (with $\mathrm{SF}_{6}$ ); however, the signal stability with $\mathrm{SF}_{6}$ is also very much better than that without. Therefore, the use of $\mathrm{SF}_{6}$ provides a distinct advantage for ES of aqueous solutions. This is particularly the case when the TC from ES is large due to the presence of electrolytes, such as buffers, at relatively high concentrations. In this case the additional increase of TC due to electrical discharge, in the absence of $\mathrm{SF}_{6}$, leads to low $\mathrm{BH}^{+}$analyte sensitivity

Figure 9. Changes of intensities of major ions, $\mathrm{Na}^{+}\left(\mathrm{H}_{2} \mathrm{O}\right)$, $\mathrm{BH}^{+}$and $\mathrm{CH}_{3} \mathrm{OH}_{2}^{+}$observed from ES of aqueous solution containing $1 \%$ methanol, $5 \times 10^{-3} \mathrm{M} \mathrm{NaCl}$ and $10^{-5} \mathrm{M} \mathrm{BHCl}$, $\mathrm{B}=$ cocaine. Upper figure shows actual recorder traces. Lower figure shows reconstructed traces that assist sorting out of traces in upper figure. Highest sensitivity and signal stability for $\mathrm{BH}^{+}$ is observed above $6 \mathrm{kV}$ with discharge suppression by $\mathrm{SF}_{6}$.

owing to increased space charge effect and to poor signal stability due to intermittency of the discharge.

A comparison between the observed currents and $\mathrm{BH}^{+}$ion intensities in methanol and in aqueous solution is shown in Figure 10. These are the data from Figures 2 and 3 for $\mathrm{BH}^{+}$with $\mathrm{SF}_{6}$ discharge suppression, plotled together to Tacilitate comparison. The $\mathrm{BH}^{+}$traces show that at $6-6.5-\mathrm{kV}$ potential, where ES works best for water as solvent, the sensitivity for $\mathrm{BH}^{+}$is lower by a factor of -4 in water relative to that in methanol. In the opening of this article, the possibility was considered that it may be the presence of electric discharges at the higher capillary voltages required for ES with water that are responsible for the poor performance of ES with water as solvent. The above results demonstrate that even when one removes the electric discharge and operates at higher capillary voltages, one still does not achieve a sensitivity equal to that obtained with methanol solutions. Because the TC are very similar (see Figure 10a), this means that the yield of gas-phase ions per charge from the droplets is lower for water relative to 

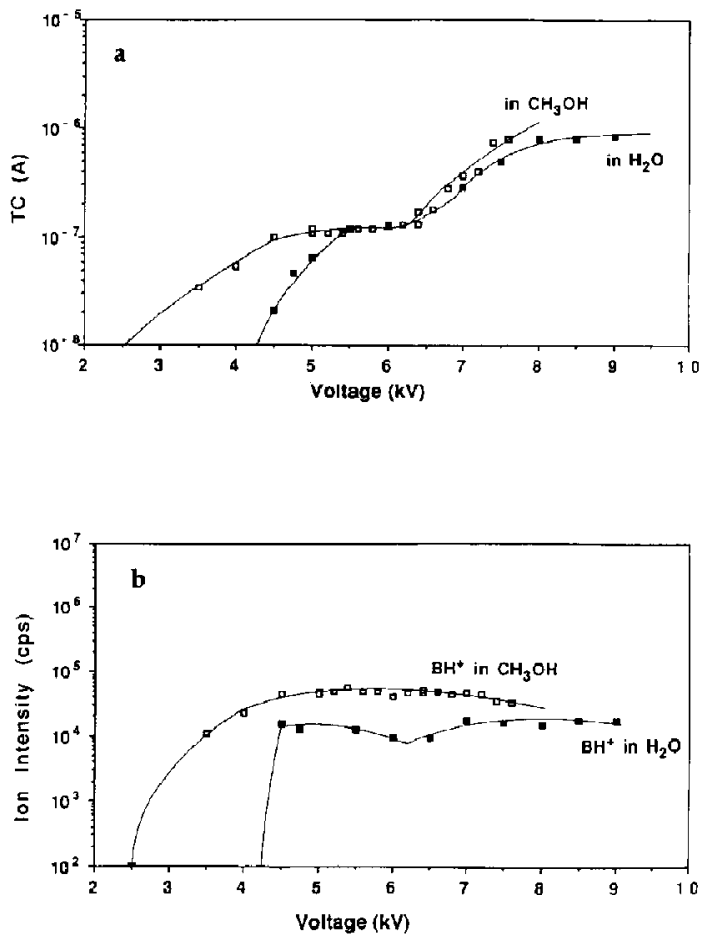

Figure 10. TC and mass analyzed $\mathrm{BH}^{+}$signal from methanol and aqueous solution $\left(+1 \%\right.$ methanol) when $10^{-5} \mathrm{M} \mathrm{BHCl}$ present in either solution. Discharge suppression by $\mathrm{SF}_{6}(40$ $\mathrm{mL} / \mathrm{min}$ ) used in both cases. The $\mathrm{BH}^{+}$intensity from the aqueous solution is lower by a factor of $\sim 4$, relative $\mathrm{BH}^{+}$from methanol.

methanol. A lower yield may be expected assuming that for a given charge on the droplets a smaller fraction of the water droplets decreases to sizes where gas-phase ion formation occurs. This may be due to larger water droplets to start with, or slower evaporation rates, or a smaller radius required by the Rayleigh [13] stability limit. An additional factor, which will operate, provided that the "ion from droplet evaporation" model of Iribarne and Thomson [14] applies, is a lower yield of gas-phase ions from water relative to methanol droplets of the same charge and size. This question was considered in our earlier publication [5] where it was shown that those authors' model predicts a lower ion evaporation efficiency from water relative to methanol droplets.

The use of $\mathrm{SF}_{6}$ for discharge suppression and a higher capillary voltage might be specially useful in gradient elution chromatography involving watermethanol or other water-organic solvent solutions because the partial equalization of analyte sensitivity and the uniform signal stability expected with $\mathrm{SF}_{6}$ over the full range of solvent composition will lead to more uniform performance over that range.

The use of $\mathrm{SF}_{6}$ to suppress electrical discharges might lead to advantages also for ES involving nega- tive ions. In that case the ES capillary is at a high negative potential and electric discharges are initiated at a lower voltage. Presumably this is due to emission of electrons from the capillary, which sustain the discharge. Electropolishing the capillary tip provides limited help. Thus, it has been observed by Yamashita and Fenn [15] that a discharge occurs even at the low capillary voltages required for ES with methanol. To suppress the discharge, these authors used a pure $\mathrm{O}_{2}$ stream in the vicinity of the capillary tip. Use of $\mathrm{O}_{2}$ was reported later also by other ES workers.

In some preliminary experiments we compared the performance of $\mathrm{SF}_{6}$ and $\mathrm{O}_{2}$, in the positive ion mode, by using $10^{-5} \mathrm{M}$ solutions of cocaine $\mathrm{HCl}$ in $99 \%$ water, $1 \%$ methanol solvent. In experiments at $6.5-\mathrm{kV}$ capillary potential, $\mathrm{O}_{2}$ gas was used instead of $\mathrm{SF}_{6}$ in the spray arrangement shown in Figure 1. The gas flow rate was increased from 0 to $1400 \mathrm{~mL} / \mathrm{min}$. With $\mathrm{SF}_{6}$, essentially complete suppression of the corona discharge was observed at flow rates $\sim 100 \mathrm{~mL} / \mathrm{min}$, in agreement with the results shown in Figure 3 . With $\mathrm{O}_{2}$, no changes of the TC were found up to the highest flows used. The ion intensities for $\mathrm{BH}^{+}$and $\mathrm{CH}_{3} \mathrm{OH}_{2}^{+}$showed very small changes, indicting minimal if any electric discharge suppression with this gas.

We plan to perform a more detailed comparison of the performance of the two gases under a variety of conditions including also the negative ion mode.

\section{Acknowledgment}

Financial support by the Premier's Council, Ontario Technology Fund is gratefully acknowledged.

\section{References}

1. Fenn, J. B.; Mann, M.; Meng, C. K.; Wong, S. K.; Whitehouse, C. M. Mass Spectrom. Rev. 1990, 9, 37.

2. Huang, E. C.; Henion, J. D. I. Am. Soc. Mass Spectrom. 1990, 1, 158 .

3. Smith, R. D.; Barinaga, C. J.; Udseth, H. R. Anal. Chem. 1988, 60, 1948.

4. Chowdhury, S. K.; Katta, V.; Chait, B. T. Rapid Commun. Mass Spectrom. 1990, 4, 81.

5. Ikonomou, M. G; Blades, A. T.; Kebarle, P. Anat. Chem. in press.

6. Smith, D. P. H. IEEE Trans. Ind. Appl. 1986, 1A-22, 527.

7. Taylor, G. I. Proc. R. Soc. Lond. A 1964, A280, 383.

8. Meek, J. M.; Craggs, J. D. Electrical Breakdown of Gases, Clarendon: Oxford, 1953.

9. Christophorou, L. G. Adv. Electron. Electron. Phys. 1987, 46,55 .

10. Ikonomou, M. G.; Blades, A. T.; Kebarle, P. Anal. Chem. $1990,62,957$.

11. Sunner, I.; Nicol, G.; Kebarle, P. Anal. Chem. 1988, 60, 1300 .

12. Busman, M.; Sunner, J.; Vogel, C. R. J. Am. Soc. Mass Spectrom. 1991, 2, 1.

13. Lord Rayleigh. Phil. Mag. 1882, 14, 31. 
14. Iribarne, I, V.; Thomson, B. A. J. Phys. Chem, 1976, 64, 2287.

15. Yamashita, M.; Fenn, J. B. 1. Phys. Chem. 1984, 88, 4671.

16. Loeb, L. B.; Kip, A. F.; Hudson, G. G.; Bennett, W. H. Phys, Rev, 1941, 60, 714.

\section{Appendix: Evaluation of Capillary Electric Fields and Voltages for the Onset of Electrospray with Different Solvents}

The equation derived by Smith [6] and discussed in the opening of this article, (see eq 1) predicts the strength of the electric field $E_{o n}$ at the capillary tip just outside the liquid, required for the onset of ES.

For a metal capillary the approximate relationship, eq 2, provides a relationship between the field $E$ and the voltage $V$

$$
\begin{gathered}
E \approx \frac{2 V}{r_{c} \ln \left(4 d / r_{c}\right)} \\
V_{o n} \approx\left(\frac{\gamma \cos \theta r_{c}}{2 \epsilon_{0}}\right)^{1 / 2} \ln \left(4 d / r_{c}\right)
\end{gathered}
$$

applied to the capillary $[6,16]$. Here $r_{c}$ is the outer radius of the capillary and $d$ is the distance between the capillary and the large, flat, counterelectrode. Combining eqs 1 and 2 one obtains eq 3 for the potential $V_{\text {on }}$ required for the onset of ES.

In the present work, $r_{c}=1.1 \times 10^{-4} \mathrm{~m}$ (see Figure 1 ) and $d=4 \times 10^{-2} \mathrm{~m}$ (see Experimental). With the use of the values $\theta=49.3 ; \epsilon_{0}=8.8 \times 10^{-12} \mathrm{~J}^{-1}, \mathrm{C}^{2}$ $\mathrm{m}^{-1} ; \gamma\left(\mathrm{CH}_{3} \mathrm{OH}\right)=2.2 \times 10^{-2} \mathrm{~N} \mathrm{~m}^{-1}, \gamma\left(\mathrm{H}_{2} \mathrm{O}\right)=7.2$ $\times 10^{-2} \mathrm{~N} \mathrm{~m}^{-1}$, one obtains for the onset voltages

$$
\begin{aligned}
V_{o n}\left(\mathrm{CH}_{3} \mathrm{OH}\right) & =2200 \mathrm{~V}(\text { eq } 3) \\
& =2000 \mathrm{~V}(\exp ) \\
V_{o n}(\mathrm{HOH}) & =3990 \mathrm{~V}(\text { eq } 3) \\
& =3800(\exp )
\end{aligned}
$$

These values are close to the measured onset potentials also given above which were obtained from Figures 3 and 4; see also the text in Results and Discussion. 